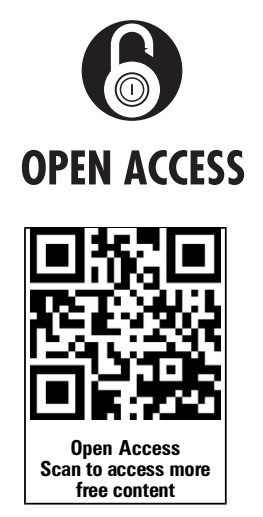

Handling editor Tore K Kvien

- Additional material is published online only. To view please visit the journal online (http://dx.doi.org/10.1136/ annrheumdis-2014-207178).

${ }^{1}$ University of California, Los Angeles, California, USA ${ }^{2}$ Charité- University Medicine Berlin, Berlin, Germany ${ }^{3}$ Rheumatology Research Unit, Nambour Hospital, Sunshine Coast, Australia

${ }^{4}$ Department of Medicine, University of Queensland, Queensland, Australia

${ }^{5}$ Centro Paulista de Investigação Clinica, São Paulo, Brazil ${ }^{6}$ Pfizer Inc, Groton, Connecticut, USA ${ }^{7}$ Pfizer Inc, New York, New York, USA ${ }^{8}$ Pfizer Inc, Collegeville, Pennsylvania, USA ${ }^{9}$ Department of Medicine, Metroplex Clinical Research Center, University of Texas Southwestern Medical Center, Dallas, Texas, USA

\section{Correspondence to} Dr Eustratios Bananis, US Medical Affairs, Inflammation \& Immunology, Global Innovative Pharma, Pfizer Inc, 500 Arcola Road, Collegeville, PA 19426, USA:

stratis.bananis@pfizer.com

Received 18 December 2014 Revised 24 June 2015 Accepted 14 July 2015 Published Online First 14 August 2015

\section{(a) CrossMark}

To cite: CharlesSchoeman C, Burmester G, Nash $P$, et al. Ann Rheum Dis 2016;75:1293-1301.

\title{
Efficacy and safety of tofacitinib following inadequate response to conventional synthetic or biological disease-modifying antirheumatic drugs
}

\author{
Christina Charles-Schoeman, ${ }^{1}$ Gerd Burmester, ${ }^{2}$ Peter Nash, ${ }^{3,4}$ Cristiano A F Zerbini, ${ }^{5}$ \\ Koshika Soma, ${ }^{6}$ Kenneth Kwok, ${ }^{7}$ Thijs Hendrikx, ${ }^{8}$ Eustratios Bananis, ${ }^{8}$ \\ Roy Fleischmann ${ }^{9}$
}

\section{ABSTRACT}

Objectives Biological disease-modifying antirheumatic drugs (bDMARDs) have shown diminished clinical response following an inadequate response (IR) to $\geq 1$ previous bDMARD. Here, tofacitinib was compared with placebo in patients with an IR to conventional synthetic DMARDs (csDMARDs; bDMARD-naive) and in patients with an IR to bDMARDs (bDMARD-IR).

Methods Data were taken from phase II and phase III studies of tofacitinib in patients with rheumatoid arthritis (RA). Patients received tofacitinib 5 or $10 \mathrm{mg}$ twice daily, or placebo, as monotherapy or with background methotrexate or other csDMARDs. Efficacy endpoints and incidence rates of adverse events (AEs) of special interest were assessed.

Results 2812 bDMARD-naive and 705 bDMARD-IR patients were analysed. Baseline demographics and disease characteristics were generally similar between treatment groups within subpopulations. Across subpopulations, improvements in efficacy parameters at month 3 were generally significantly greater for both tofacitinib doses versus placebo. Clinical response was numerically greater with bDMARD-naive versus bDMARD-IR patients (overlapping 95\% Cls). Rates of safety events of special interest were generally similar between tofacitinib doses and subpopulations; however, patients receiving glucocorticoids had more serious AEs, discontinuations due to AEs, serious infection events and herpes zoster. Numerically greater clinical responses and incidence rates of AEs of special interest were generally reported for tofacitinib $10 \mathrm{mg}$ twice daily versus tofacitinib 5 mg twice daily (overlapping 95\% Cls). Conclusions Tofacitinib demonstrated efficacy in both bDMARD-naive and bDMARD-IR patients with RA. Clinical response to tofacitinib was generally numerically greater in bDMARD-naive than bDMARD-IR patients.

The safety profile appeared similar between subpopulations.

Trial registration numbers (NCT00413660, NCT0050446, NCT00603512, NCT00687193, NCT00960440, NCT00847613, NCT00814307, NCT00856544, NCT00853385).

\section{INTRODUCTION}

Increasing evidence suggests that early, aggressive intervention has a beneficial impact on the clinical response to therapy in patients with rheumatoid arthritis (RA), and delay in initiation of treatment and prior disease-modifying antirheumatic drug (DMARD) exposure has been associated with decreased response. ${ }^{1-9}$ Although there are limited data in randomised controlled trials on the efficacy treatment in biological DMARD (bDMARD)-naive patients versus patients with an inadequate response (IR) to bDMARDs (bDMARD-IR), published reports of bDMARDs have generally shown less clinical response when a bDMARD is used after an IR to at least one previous bDMARD. ${ }^{10-21}$ It is important that new RA therapies demonstrate efficacy and tolerability in RA patient populations with varying disease duration and prior treatment exposure to reflect the variability seen in clinical practice.

Tofacitinib is an oral Janus kinase inhibitor for the treatment of RA. The clinical efficacy and safety of tofacitinib 5 and $10 \mathrm{mg}$ twice daily as monotherapy or in combination with conventional synthetic DMARDs (csDMARDs) for the treatment of RA has been reported previously in phase $\mathrm{II}^{22-26}$ phase $\mathrm{III}^{27-32}$ and long-term extension (LTE) clinical studies. ${ }^{33}$

Patients receiving tofacitinib in the RA development programme included those who were naive to or had an IR to bDMARDs. The objectives of these analyses were to compare the efficacy and safety of tofacitinib 5 and $10 \mathrm{mg}$ twice daily versus placebo in patients who had an IR to csDMARDs only (bDMARD-naive), and patients with an IR to previous bDMARDs including tumour necrosis factor inhibitors (TNFi; bDMARD-IR).

\section{METHODS}

\section{Clinical studies}

Phase II studies

The four phase II studies were randomised, doubleblind, placebo-controlled studies: A3921025 (NCT00413660), A3921035 (NCT00550446), A3921039 (NCT00603512) and A3921040 (NCT00687193). Patients received tofacitinib 1, 3, 5,10 or $15 \mathrm{mg}$ twice daily, tofacitinib $20 \mathrm{mg}$ once daily (A3921025) or placebo, as monotherapy (A3921035 and A3921040) or in combination with background methotrexate (A3921025 and A3921039). A3921035 included a monotherapy adalimumab arm. Patients had an IR to a bDMARD or csDMARD (A3921035 and A3921040), or methotrexate (A3921025 and A3921039). Full details have been published previously. $^{22} 24-26$ 
Phase III studies

The five phase III studies were double-blind, placebo-controlled, global studies: ORAL Step (A3921032; NCT00960440), ORAL Scan (A3921044; NCT00847613), ORAL Solo (A3921045; NCT00814307), ORAL Sync (A3921046; NCT00856544) and ORAL Standard (A3921064; NCT00853385). Patients had an IR to a bDMARD or csDMARD (ORAL Solo and ORAL Sync), methotrexate (ORAL Scan and ORAL Standard) or TNFi (ORAL Step). Patients with RA received tofacitinib $5 \mathrm{mg}$ twice daily, tofacitinib $10 \mathrm{mg}$ twice daily or placebo, as monotherapy (ORAL Solo), with background csDMARDs (ORAL Sync) or with background methotrexate (ORAL Standard, ORAL Scan, ORAL Step). ORAL Standard included an adalimumab plus methotrexate arm. In ORAL Sync, ORAL Standard and ORAL Scan, placebo patients who did not achieve $\geq 20 \%$ decrease in tender/swollen joints were treated with tofacitinib at month 3. All remaining placebo patients were treated with tofacitinib at month 6. In ORAL Step and ORAL Solo, all placebo patients were treated with tofacitinib at month 3 . Full details have been published previously. ${ }^{27-31}$ After the publication of ORAL Standard, one of its study sites (nine patients randomised) was found to be non-compliant to study procedures and those patients have been removed from the efficacy analyses presented here.

\section{Patient subpopulations}

IR was defined as discontinuation due to lack of efficacy, an adverse event (AE), or both, in all studies except for study A3921039, which did not collect the same detailed information.

Two analysis cohorts were included: pooled phase II and phase III studies (P2/P3) cohort, and the pooled phase III studies (P3) cohort. The P2/P3 cohort included patients from the four phase II and five phase III studies. The P3 cohort included patients from the five phase III studies.

The following patient subpopulations were analysed in both P2/P3 and P3 cohorts according to prior DMARD experience and response to DMARD therapy:

- bDMARD-naive: patients who had an IR to csDMARDs only

- bDMARD-IR: patients with an IR to previous TNFi or other bDMARDs.

For the P2/P3 cohort, the following patient subpopulations were analysed according to previous TNFi exposure:

- bDMARD-naive: patients who had an IR to csDMARDs only

- patients who were IR to one previous TNFi

- patients who were IR to multiple previous TNFi ( $\geq 2$ previous TNFi).

\section{Efficacy and safety analyses}

The following efficacy parameters were assessed: American College of Rheumatology (ACR) 20/50/70 response rates; disease activity score (DAS)28-4(erythrocyte sedimentation rate) (ESR); Health Assessment Questionnaire-Disability Index (HAQ-DI); Clinical Disease Activity Index (CDAI) and Simplified Disease Activity Index (SDAI). Efficacy comparisons were performed on the P2/P3 cohort at months 3 and 6 .

Safety parameters assessed using exposure estimates and incidence rates (patients with event per 100 patient-years of observation) included discontinuations due to AEs; serious AEs (SAEs); all-cause mortality; malignancies (excluding nonmelanoma skin cancer (NMSC)); lymphoma/lymphoproliferative disorders; all herpes zoster (HZ; serious and non-serious); serious HZ; serious infection events (SIEs); tuberculosis (TB); opportunistic infections (excluding TB) and major adverse cardiovascular events. Safety was assessed in the P3 cohort during months 0-6 for placebo and months 0-24 for tofacitinib. Patients initially treated with placebo were counted in the placebo group until treatment with tofacitinib. Safety endpoints were analysed in the P3 cohort only and not the P2/P3 cohort due to the phase II studies containing multiple doses and titrations of tofacitinib, thereby making it difficult to assign a safety event to a specific tofacitinib 5 or $10 \mathrm{mg}$ twice daily dose.

\section{Statistical analyses}

All efficacy and safety analyses were based on the full analyses set-all patients who were randomised and received $\geq 1$ dose of study treatment (tofacitinib or placebo).

For binary efficacy variables, missing values were computed using non-responder imputation, except for CDAI and SDAI (low-disease activity or remission) where observed case data were used. Testing for treatment differences between tofacitinib and placebo was based on the normal approximation. For continuous variables, missing values were handled by the linear mixed-effect models (used to assess the treatment effects). For the exploratory analysis of tofacitinib versus placebo at month 3 , statistical significance was declared at $\mathrm{p}<0.05$, without multiplicity corrections to preserve type I error.

The 95\% CIs were presented for the bDMARD-naive and bDMARD-IR subpopulations. For binary efficacy variables, exact binomial intervals were calculated, and for continuous efficacy variables, normal approximation was used.

All safety analyses were based on observed cases. Incidence rates for safety parameters were calculated by exposure and dose. Incidence rates were based on the number of patients with an event and total exposure time censored at time of event, death or withdrawal from the study; 95\% CIs for incidence rates were based on maximum likelihood estimation. A subanalysis of incidence rates for safety events of special interest for patients with/without concomitant glucocorticoid treatment was also performed.

\section{RESULTS}

\section{Patients}

A total of 1071,1090 and 651 bDMARD-naive patients were randomised to receive tofacitinib $5 \mathrm{mg}$ twice daily, tofacitinib $10 \mathrm{mg}$ twice daily and placebo, respectively. In the bDMARD-IR subpopulation, 259, 253 and 193 patients were randomised to receive tofacitinib $5 \mathrm{mg}$ twice daily, tofacitinib $10 \mathrm{mg}$ twice daily and placebo, respectively. In the bDMARD-IR group, discontinuations of prior bDMARDs occurred due to lack of efficacy (68.4\%), AEs (7.2\%) and both lack of efficacy and AEs (24.4\%).

Baseline demographics and disease characteristics were generally similar for tofacitinib versus placebo groups (table 1). Compared with bDMARD-naive patients, a higher proportion of bDMARD-IR patients were Caucasian, had a higher mean body mass index, were from the USA, had longer mean disease duration and slightly greater mean disease activity at baseline (table 1). Compared with bDMARD-IR patients, higher proportions of bDMARD-naive patients were from Latin America or rest of world, had previously taken csDMARDs other than methotrexate and were rheumatoid factor positive (table 1).

\section{Efficacy}

Tofacitinib $5 \mathrm{mg}$ twice daily

Tofacitinib $5 \mathrm{mg}$ twice daily versus placebo

In both bDMARD-naive and bDMARD-IR patients, a significantly $(p<0.05)$ greater proportion of patients in the tofacitinib 
Table 1 Patient demographics and baseline disease characteristics in the P2/P3 cohort

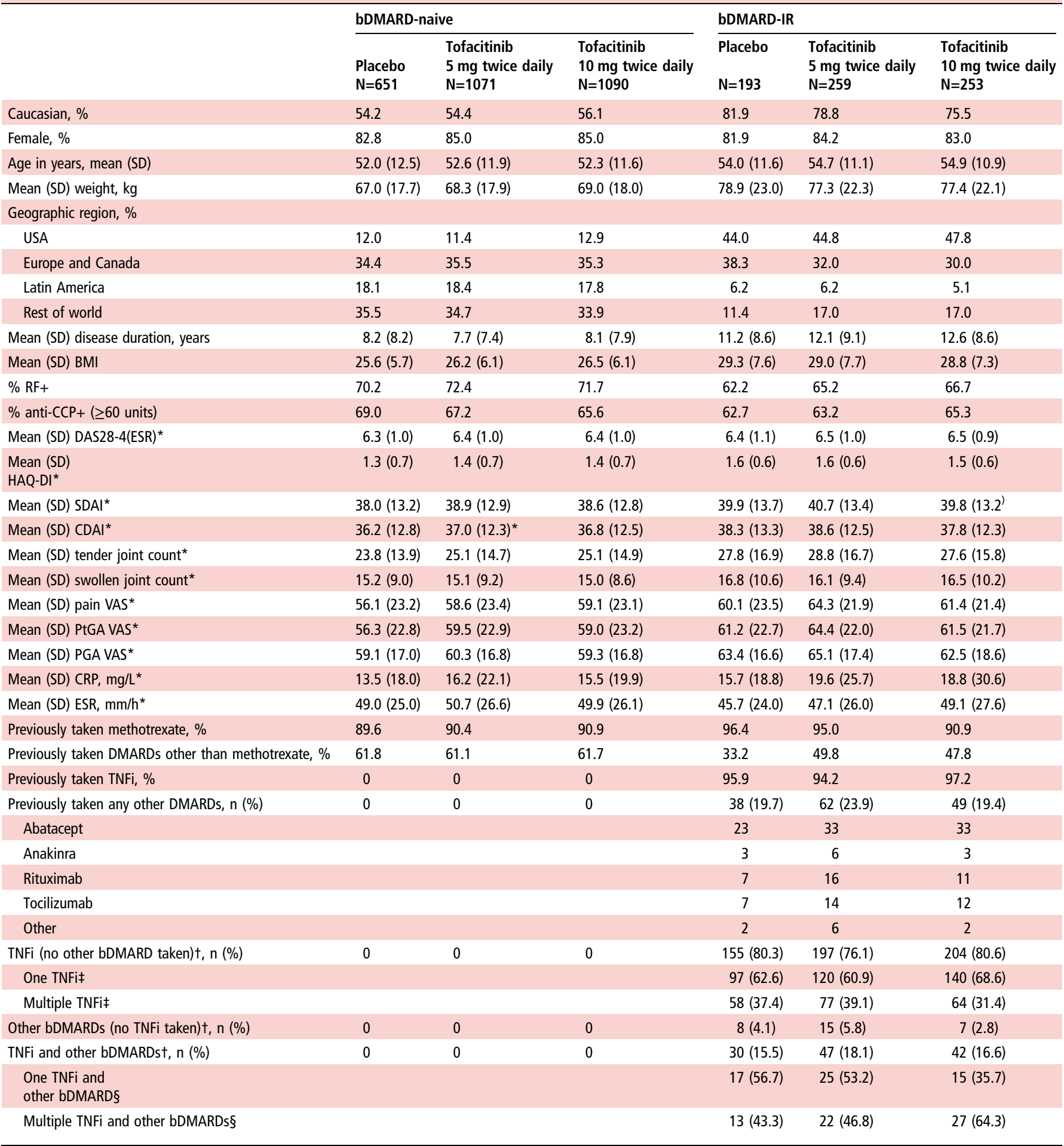

${ }^{*}$ The denominators were slightly less than the numbers of randomised patients (Ns), based on data collection and availability.

$\dagger \%$ based on denominator of the total number of patients (per treatment) in the bDMARD-IR population, and these groups are mutually exclusive.

$¥ \%$ based on denominator of the total number of patients (per treatment) who had previously taken TNFi in the bDMARD-IR population.

$\S \%$ based on denominator of the total number of patients (per treatment) who had previously taken TNFi and other bDMARDs in the bDMARD-IR population.

bDMARD, biological disease-modifying antirheumatic drug; BMI, body mass index; CCP, cyclic citrullinated peptide; CDAl, Clinical Disease Activity Index; CRP, C reactive protein; DAS,

disease activity score; DMARD, disease-modifying antirheumatic drug; ESR, erythrocyte sedimentation rate; HAQ-DI, Health Assessment Questionnaire-Disability Index; IR, inadequate responders; N, number of patients included in analysis; P2/P3, phase II/phase III; PGA, Physician Global Assessment of Arthritis; PtGA, Patient Global Assessment of Arthritis; RF, rheumatoid factor; SDAI, Simplified Disease Activity Index; TNFi, tumour necrosis factor inhibitor; VAS, visual analogue scale.

$5 \mathrm{mg}$ twice daily group versus placebo achieved ACR20/50/70 response rates at month 3 (figure 1). Furthermore, least-squares mean changes from baseline at month 3 in HAQ-DI and DAS28-4(ESR) (figure 2), and improvements in other efficacy parameters, were significantly $(\mathrm{p}<0.05)$ higher for tofacitinib $5 \mathrm{mg}$ twice daily versus placebo, except the percentage of patients achieving improvements $\geq 0.22$ in HAQ-DI for bDMARD-IR patients (table 2). 
Figure 1 (A) ACR20, (B) ACR50 and (C) ACR70 response rates $(95 \% \mathrm{Cl})$ at month 3 for bDMARD-naive versus bDMARD-IR populations in phase (P)2/ P3 cohort (FAS, NRI). ${ }^{*} p<0.05$; ${ }^{* *} p<0.001 ;{ }^{* * *} p<0.0001$ vs placebo. No preservation of type I error or multiple-comparisons correction was applied to $p$ values as statistical significance defined as $p<0.05$ was exploratory in nature; $95 \% \mathrm{Cls}$ are exact binomial confidence intervals for single proportion. ACR 20/50/70, proportion of patients achieving $>20 \%$, $>50 \%$, and $>70 \%$ improvement in American College of Rheumatology criteria; bDMARD, biologic disease-modifying antirheumatic drug; BID, twice daily; $\mathrm{Cl}$, confidence interval; FAS, full analysis set; IR, inadequate responders; NRI, non-responder imputation.
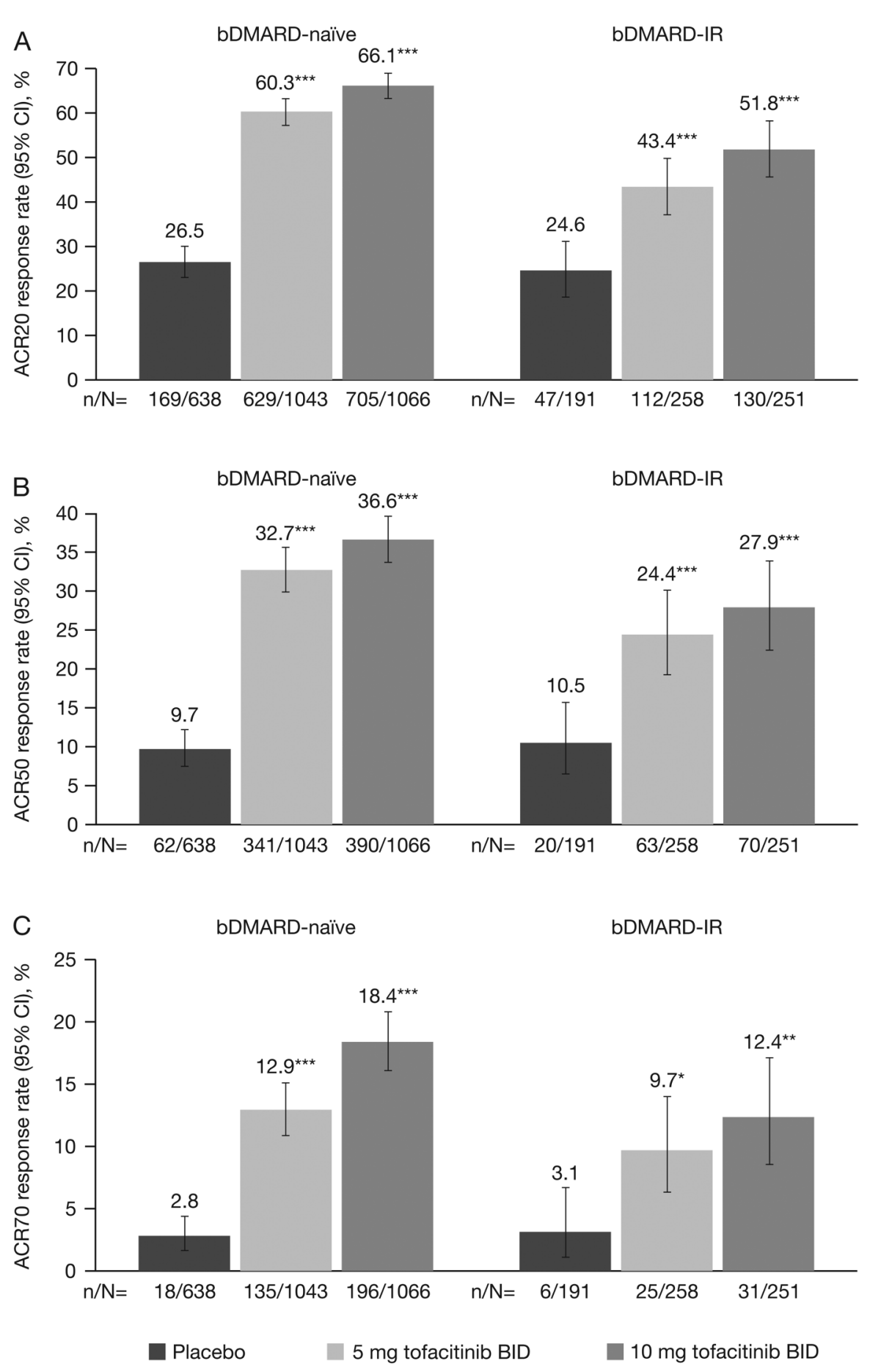

Tofacitinib $5 \mathrm{mg}$ twice daily versus placebo by prior TNFi exposure For the bDMARD-naive subpopulation, improvements were significantly $(\mathrm{p}<0.05)$ greater for tofacitinib $5 \mathrm{mg}$ twice daily versus placebo across all efficacy endpoints at month 3 (see online supplementary table S1). In the 1 and $\geq 2$ previous TNFi groups, tofacitinib $5 \mathrm{mg}$ twice daily resulted in significant $(p<0.05)$ improvements versus placebo in efficacy endpoints at month 3, except DAS28-4(ESR) $\leq 3.2$ and $<2.6$, and HAQ-DI $\leq 0.5$ for one previous TNFi, and ACR70, $\mathrm{CDAI} \leq 10$ and $\leq 2.8$, HAQ-DI $\leq 0.5$ and $\mathrm{SDAI} \leq 11$ for $\geq 2$ previous TNFi, although all responses were numerically higher for tofacitinib versus placebo (see online supplementary table S1).
Tofacitinib $5 \mathrm{mg}$ twice daily bDMARD-naive versus bDMARD-IR analyses

At months 3 and 6, improvements in clinical responses were numerically greater for bDMARD-naive versus bDMARD-IR patients, except SDAI $\leq 3.3$ at month 3 and DAS28-4(ESR) $\leq 3.2$ at month 6 ; $95 \%$ CIs were overlapping for most efficacy parameters, except ACR20 at month 3 (figure 1; tables 2 and 3).

At month 3, improvements in clinical responses were numerically greater for bDMARD-naive patients versus one previous TNFi patient versus $\geq 2$ previous TNFi patients for tofacitinib $5 \mathrm{mg}$ twice daily, except CDAI and SDAI remission endpoints; 95\% CIs were overlapping for most efficacy parameters, except ACR20 (see online supplementary table S1). 
A

bDMARD-naïve

bDMARD-IR

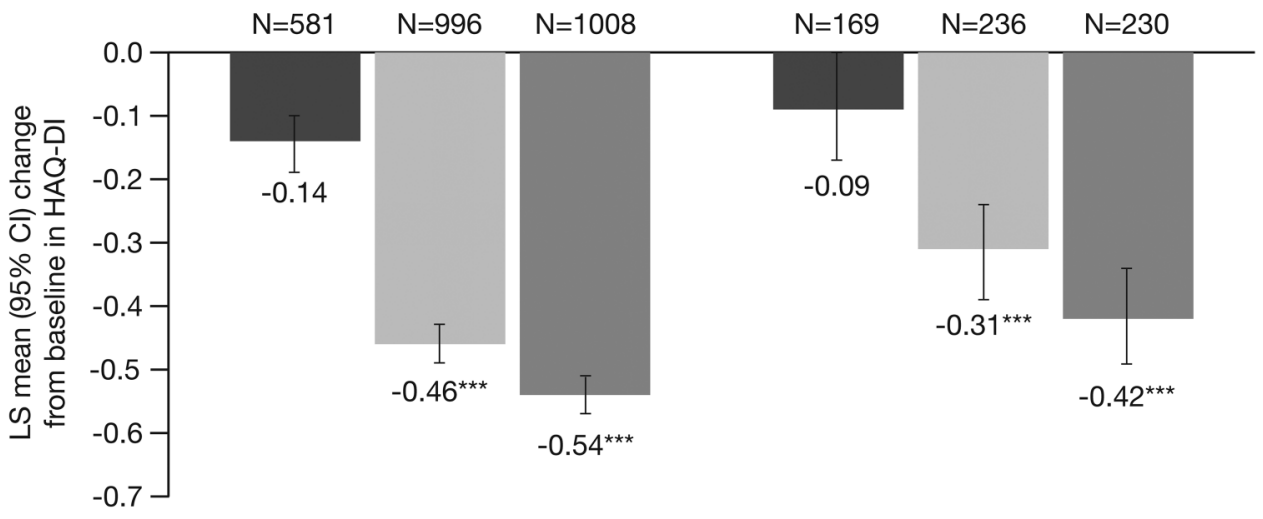

B

bDMARD-naïve

bDMARD-IR

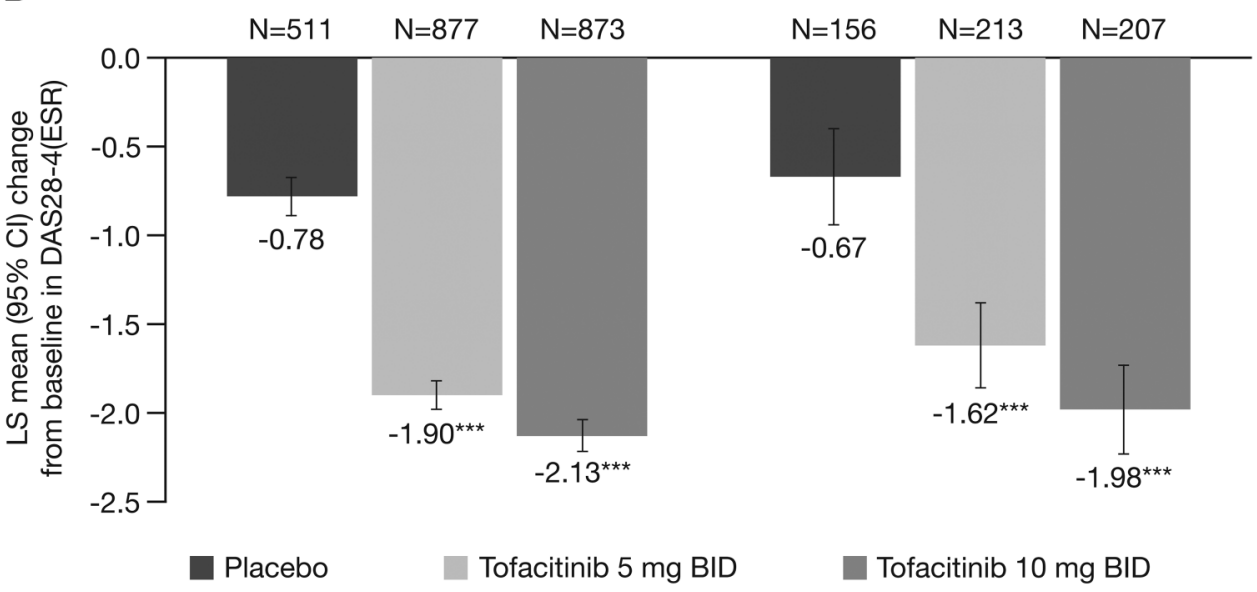

Figure 2 LS mean change from baseline (95\% CI) at month 3 in (A) HAQ-DI and (B) DAS28-4(ESR) for bDMARD-naive versus bDMARD-IR populations in the phase (P)2/P3 cohort (FAS, longitudinal model). ${ }^{* *} \mathrm{p}<0.0001$ vs placebo. No preservation of type I error or multiple-comparisons correction was applied to $p$ values as statistical significance defined as $p<0.05$ was exploratory in nature; $95 \%$ Cls are based on normal approximation. bDMARD, biologic disease-modifying antirheumatic drug; BID, twice daily; CI, confidence interval; DAS, disease activity score; ESR, erythrocyte sedimentation rate; FAS, full analysis set; HAQ-DI, Health Assessment Questionnaire-Disability Index; IR, inadequate responders; LS, least squares.

Tofacitinib $10 \mathrm{mg}$ twice daily

Tofacitinib $10 \mathrm{mg}$ twice daily versus placebo

In both bDMARD-naive and bDMARD-IR patients, improvements in all efficacy parameters were significantly $(p<0.05)$ greater for tofacitinib $10 \mathrm{mg}$ twice daily versus placebo (figures 1 and 2 and table 2).

\section{Tofacitinib $10 \mathrm{mg}$ twice daily versus placebo by prior TNFi exposure}

For the bDMARD-naive, and 1 and $\geq 2$ previous TNFi groups, improvements were significantly $(\mathrm{p}<0.05)$ greater for tofacitinib $10 \mathrm{mg}$ twice daily versus placebo across all efficacy endpoints at month 3, except ACR70, CDAI $\leq 10$ and $\leq 2.8$, and DAS28-4 $(\mathrm{ESR})<2.6$ for $\geq 2$ previous TNFi, although all responses were numerically higher for tofacitinib versus placebo (see online supplementary table S1).

\section{Tofacitinib $10 \mathrm{mg}$ twice daily DDMARD-naive versus DDMARD-IR analyses}

At months 3 and 6, improvements in clinical responses were numerically greater for bDMARD-naive versus bDMARD-IR patients, except DAS28-4(ESR)<2.6 at month 6; 95\% CIs were overlapping for most efficacy parameters, except ACR20 at month 3 (figures 1 and 2; tables 2 and 3).
Improvements in clinical responses at month 3 were numerically greater for all efficacy parameters for bDMARD-naive patients versus one previous TNFi patient versus $\geq 2$ previous TNFi patients with the following exceptions: $\mathrm{SDAI}<11$ and LS mean change from baseline in HAQ-DI (in bDMARD-naive and one previous TNFi group); LS mean change from baseline in DAS28-4(ESR) (in bDMARD-naive and $\geq 2$ previous TNFi groups) ACR20 (in one previous TNFi and $\geq 2$ previous TNFi groups); 95\% CIs were overlapping for most efficacy parameters, except ACR20 (see online supplementary table S1).

\section{Safety: tofacitinib $5 \mathrm{mg}$ twice daily and tofacitinib $10 \mathrm{mg}$ twice daily}

Incidence rates were numerically higher for both tofacitinib doses versus placebo for SIEs, HZ and malignancies (excluding NMSC); bDMARD-IR versus bDMARD-naive subpopulations for discontinuations due to AEs, $\mathrm{HZ}$ and malignancies (excluding NMSC) (table 4). Despite the noted numerical differences, 95\% CIs were generally overlapping when comparing each tofacitinib dose versus placebo within each subpopulation. The CIs of incidence rates for safety events in the placebo and bDMARD-IR groups were wider versus the bDMARD-naive tofacitinib groups due to the lower total exposure (table 4). 
Table 2 Efficacy responses at month 3 for bDMARD-naive versus bDMARD-IR in the P2/P3 cohort

\begin{tabular}{|c|c|c|c|c|c|c|}
\hline \multirow[b]{2}{*}{$\begin{array}{l}\text { Parameter, \% } \\
(95 \% \mathrm{Cl})\end{array}$} & \multicolumn{3}{|l|}{ bDMARD-naive } & \multicolumn{3}{|l|}{ bDMARD-IR } \\
\hline & $\begin{array}{l}\text { Placebo } \\
N=638\end{array}$ & $\begin{array}{l}\text { Tofacitinib } \\
5 \mathrm{mg} \text { twice daily } \\
\mathrm{N}=1043\end{array}$ & $\begin{array}{l}\text { Tofacitinib } \\
10 \mathrm{mg} \text { twice daily } \\
\mathrm{N}=1066\end{array}$ & $\begin{array}{l}\text { Placebo } \\
\mathrm{N}=191\end{array}$ & $\begin{array}{l}\text { Tofacitinib } 5 \mathrm{mg} \\
\text { twice daily } \\
\mathrm{N}=258\end{array}$ & $\begin{array}{l}\text { Tofacitinib } \\
10 \mathrm{mg} \text { twice daily } \\
\mathrm{N}=251\end{array}$ \\
\hline CDAI $\leq 10 \dagger$ & 14.3 (11.5 to 17.4$)$ & $32.4^{* * *}$ (29.5 to 35.4$)$ & $39.8^{* * *}$ (36.8 to 42.9 ) & 14.4 (9.4 to 20.6$)$ & $29.5^{* *}$ (23.8 to 35.8$)$ & $35.9^{* * *}(29.7$ to 42.5$)$ \\
\hline $\mathrm{CDAl} \leq 2.8 \ddagger$ & 0.7 (0.2 to 1.8$)$ & $6.4^{* * *}$ (5.0 to 8.2 ) & $9.0^{* * *}$ (7.3 to 11.0$)$ & 1.2 (0.1 to 4.3$)$ & $5.9^{*}$ (3.3 to 9.7$)$ & $6.5^{*}(3.7$ to 10.5$)$ \\
\hline SDAI $\leq 11 \dagger$ & 14.2 (11.4 to 17.3$)$ & $34.6^{* * *}$ (31.6 to 37.6$)$ & $41.1^{* * *}$ (38.0 to 44.2$)$ & $13.8(8.9$ to 19.9$)$ & $29.8^{* * *}$ (24.0 to 36.1$)$ & $38.3^{* * *}(32.0$ to 44.9$)$ \\
\hline SDAI $\leq 3.3 \ddagger$ & 0.7 (0.2 to 1.8$)$ & $6.4^{* * *}$ (4.9 to 8.1$)$ & $9.3^{* * *}$ (7.6 to 11.3 ) & 0.6 (0.0 to 3.3$)$ & $6.8^{* *}$ (3.9 to 10.8$)$ & $8.3^{* * *}(5.0$ to 12.6$)$ \\
\hline $\begin{array}{l}\text { DAS28-4 (ESR) } \\
\leq 3.2+\end{array}$ & 4.5 (3.0 to 6.5$)$ & $16.6^{* * *}$ (14.3 to 19.2$)$ & $22.9^{* * *}$ (20.3 to 25.8 ) & 5.1 (2.4 to 9.5$)$ & $12.7^{*}$ (8.6 to 17.7 ) & $17.8^{* * *}$ (13.0 to 23.4$)$ \\
\hline $\begin{array}{l}\text { DAS28-4 (ESR) } \\
<2.6 \ddagger\end{array}$ & 2.3 (1.2 to 3.8$)$ & $7.3^{* * *}$ (5.7 to 9.2 ) & $11.5^{* * *}$ (9.5 to 13.7$)$ & $2.3(0.6$ to 5.7$)$ & $6.6^{*}$ (3.7 to 10.6$)$ & $8.4^{*}(5.2$ to 12.9$)$ \\
\hline $\begin{array}{l}\text { HAQ-DI } \\
\text { improvement } \geq 0.22\end{array}$ & 28.7 (24.5 to 33.1$)$ & $52.9^{* * *}$ (49.5 to 56.3$)$ & $59.8^{* * *}$ (56.4 to 63.0$)$ & $36.9(29.8$ to 44.4$)$ & 45.7 (39.4 to 52.2 ) & $55.3^{* *}(48.7$ to 61.7$)$ \\
\hline $\begin{array}{l}\text { HAQ-DI } \\
\text { improvement } \geq 0.5\end{array}$ & $18.2(14.8$ to 22.1$)$ & $40.3^{* * *}$ (37.0 to 43.6$)$ & $46.1^{* * *}$ (42.8 to 49.5$)$ & 20.1 (14.5 to 26.7) & $31.0^{*}$ (25.3 to 37.2$)$ & $39.2^{* * *}$ (33.0 to 45.8$)$ \\
\hline
\end{tabular}

${ }^{*} \mathrm{p}<0.05 ;{ }^{* *} \mathrm{p}<0.001 ;{ }^{* *} \mathrm{p}<0.0001$ versus placebo. No preservation of type I error or multiple-comparisons correction was applied to $\mathrm{p}$ values as statistical significance defined as $\mathrm{p}<0.05$ was exploratory in nature; $95 \% \mathrm{Cls}$ are exact binomial Cls for single proportions.

tLow-disease activity.

‡Disease remission.

DAS28-4(ESR) and HAQ-DI data were FAS, NRI; CDAI and SDAI data were FAS, observed case; percentages were based on the number of patients available for each parameter analysis. bDMARD, biological disease-modifying antirheumatic drug; CDAl, Clinical Disease Activity Index; DAS, disease activity score; ESR, erythrocyte sedimentation rate; FAS, full analysis set; HAQ-DI, Health Assessment Questionnaire-Disability Index; IR, inadequate responders; N, number of patients with available ACR data at month 3; NRI, non-responder imputation; P2/P3, phase II/phase III; SDAI, Simplified Disease Activity Index.

Patients who received glucocorticoids had a higher incidence rate of SAEs, discontinuation due to AEs, SIEs and $\mathrm{HZ}$ versus patients who did not receive glucocorticoids (see online supplementary table S2). No differences in baseline demographics or efficacy were observed between the two subpopulations (data not shown).

\section{DISCUSSION}

To the best of our knowledge, this is the first study to analyse the efficacy and safety of an approved RA treatment in bDMARD-naive versus bDMARD-IR populations using pooled data from a large, randomised clinical trial programme.

Tofacitinib was effective in reducing the signs and symptoms of RA when used before or after bDMARDs. In both bDMARD-naive and bDMARD-IR patients in the P2/P3 cohort, improvements in efficacy parameters at month 3 were significantly $(\mathrm{p}<0.05)$ greater for both tofacitinib doses versus placebo (except improvements $\geq 0.22$ in HAQ-DI for
bDMARD-IR patients who received tofacitinib $5 \mathrm{mg}$ twice daily). In general, improvements in clinical responses at months 3 and 6 were numerically greater for bDMARD-naive versus bDMARD-IR patients, with overlapping 95\% CIs. In particular, the proportions of patients achieving ACR20/50/70 responses were higher in the bDMARD-naive versus the bDMARD-IR subpopulation; the differences between the subpopulations for endpoints such as changes in DAS28-4(ESR), CDAI or SDAI, or achieving DA28-4(ESR), CDAI or SDAI remission or lowdisease activity were less prominent. Of note, bDMARD-IR patients had longer disease duration and slightly greater disease activity at baseline compared with bDMARD-naive patients, which could have influenced these results. Although no formal comparisons were made, numerically greater clinical responses were generally reported for tofacitinib $10 \mathrm{mg}$ twice daily versus tofacitinib $5 \mathrm{mg}$ twice daily; however, both tofacitinib doses reported significant improvements versus placebo across efficacy endpoints in both subpopulations.

\begin{tabular}{|c|c|c|c|c|}
\hline \multirow[b]{2}{*}{ Parameter, \% $(95 \% \mathrm{Cl})$} & \multicolumn{2}{|l|}{ bDMARD-naive } & \multicolumn{2}{|l|}{ bDMARD-IR } \\
\hline & $\begin{array}{l}\text { Tofacitinib } 5 \mathrm{mg} \text { twice daily } \\
\mathrm{N}=975\end{array}$ & $\begin{array}{l}\text { Tofacitinib } 10 \mathrm{mg} \text { twice daily } \\
\mathrm{N}=997\end{array}$ & $\begin{array}{l}\text { Tofacitinib } 5 \mathrm{mg} \text { twice daily } \\
\mathrm{N}=250\end{array}$ & $\begin{array}{l}\text { Tofacitinib } 10 \mathrm{mg} \text { twice daily } \\
\mathrm{N}=245\end{array}$ \\
\hline ACR20 & 51.9 (48.7 to 55.1$)$ & 53.8 (50.6 to 56.9$)$ & 45.6 (39.3 to 52.0$)$ & 53.1 (46.6 to 59.4$)$ \\
\hline ACR50 & 32.9 (30.0 to 36.0$)$ & 36.5 (33.5 to 39.6$)$ & 32.0 (26.3 to 38.2$)$ & 29.8 (24.1 to 36.0$)$ \\
\hline ACR70 & 15.0 (12.8 to 17.4$)$ & $19.2(16.8$ to 21.7$)$ & 14.8 (10.6 to 19.8$)$ & 17.6 (13.0 to 22.9$)$ \\
\hline DAS28-4(ESR) $\leq 3.2^{*}$ & 16.3 (13.9 to 19.0$)$ & 23.3 (20.5 to 26.2$)$ & $18.3(13.5$ to 24.0$)$ & 23.0 (17.6 to 29.1$)$ \\
\hline DAS28-4(ESR) $<2.6 \dagger$ & 7.2 (5.6 to 9.2 ) & $12.6(10.5$ to 15.0$)$ & 7.1 (4.1 to 11.3 ) & 13.1 (8.9 to 18.2$)$ \\
\hline HAQ-DI improvement $\geq 0.22$ & $54.6(51.3$ to 58.0$)$ & 58.6 (55.3 to 61.9$)$ & 47.4 (41.0 to 53.8$)$ & 51.9 (45.3 to 58.4$)$ \\
\hline HAQ-DI improvement $\geq 0.5$ & 41.7 (38.3 to 45.0$)$ & $46.7(43.3$ to 50.1$)$ & 33.5 (27.6 to 39.8$)$ & 38.8 (32.6 to 45.3$)$ \\
\hline
\end{tabular}


Table 4 Incidence rates (patients with event per 100 patient-years; $95 \% \mathrm{CI}$ ) for safety events of special interest in bDMARD-naive versus bDMARD-IR subpopulations in the P3 cohort

\begin{tabular}{|c|c|c|c|c|c|c|}
\hline \multirow[b]{2}{*}{$\begin{array}{l}\text { Safety event, incidence rate } \\
\text { (patients with event per } 100 \\
\text { patient-years; } 95 \% \mathrm{Cl} \text { ) }\end{array}$} & \multicolumn{3}{|l|}{ bDMARD-naive } & \multicolumn{3}{|l|}{ bDMARD-IR } \\
\hline & $\begin{array}{l}\text { Placebo } \\
\mathrm{N}=465\end{array}$ & $\begin{array}{l}\text { Tofacitinib } 5 \mathrm{mg} \\
\text { twice daily } \\
\mathrm{N}=893\end{array}$ & $\begin{array}{l}\text { Tofacitinib } 10 \mathrm{mg} \\
\text { twice daily } \\
\mathrm{N}=898\end{array}$ & $\begin{array}{l}\text { Placebo } \\
\mathrm{N}=181\end{array}$ & $\begin{array}{l}\text { Tofacitinib } 5 \mathrm{mg} \\
\text { twice daily } \\
\mathrm{N}=247\end{array}$ & $\begin{array}{l}\text { Tofacitinib } 10 \mathrm{mg} \\
\text { twice daily } \\
\mathrm{N}=241\end{array}$ \\
\hline Exposure, patient-years & 149.5 & 885.5 & 917.4 & 42.5 & 170.5 & 154.8 \\
\hline All SAEs & 15.0 (9.9 to 22.7$)$ & $12.2(10.0$ to 14.8$)$ & 9.6 (7.8 to 11.9$)$ & $19.0(9.5$ to 38.0$)$ & $13.0(8.5$ to 20.0$)$ & $11.3(7.0$ to 18.1$)$ \\
\hline Discontinuations due to AEs & 10.1 (6.1 to 16.7$)$ & 9.1 (7.3 to 11.3 ) & 9.6 (7.8 to 11.9$)$ & 18.9 (9.5 to 37.8$)$ & $14.8(10.0$ to 21.9$)$ & $15.0(10.0$ to 22.5$)$ \\
\hline All serious infections & 2.0 (0.6 to 6.2$)$ & 3.4 (2.4 to 4.9$)$ & 3.5 (2.5 to 4.9$)$ & 0 & $2.3(0.9$ to 6.3$)$ & $3.2(1.3$ to 7.8$)$ \\
\hline $\begin{array}{l}\text { Herpes zoster (all—serious and } \\
\text { non-serious) }\end{array}$ & $2.0(0.7$ to 6.3$)$ & 4.0 (2.8 to 5.5$)$ & 4.4 (3.2 to 6.0$)$ & 0 & $5.4(2.8$ to 10.4$)$ & 5.4 (2.7 to 10.7$)$ \\
\hline Herpes zoster (serious) & 0 & $0.3(0.1$ to 1.1$)$ & $0.3(0.1$ to 1.0$)$ & 0 & $0.6(0.1$ to 4.2$)$ & 0 \\
\hline Herpes zoster (non-serious) & $2.0(0.7$ to 6.3$)$ & $3.6(2.5$ to 5.1$)$ & 4.1 (3.0 to 5.7$)$ & 0 & 4.8 (2.4 to 9.6$)$ & $5.4(2.7$ to 10.7$)$ \\
\hline Tuberculosis & 0 & 0 & 0.8 (0.4 to 1.6$)$ & 0 & 0 & 0 \\
\hline $\begin{array}{l}\text { Opportunistic infections } \\
\text { (excluding tuberculosis) }\end{array}$ & 0 & $0.3(0.1$ to 1.1$)$ & $0.4(0.2$ to 1.2$)$ & 0 & 0 & 0 \\
\hline Malignancy (excluding NMSC) & 0 & $0.6(0.2$ to 1.4$)$ & $0.9(0.4$ to 1.7$)$ & 0 & $1.2(0.3$ to 4.7$)$ & $1.9(0.6$ to 6.0$)$ \\
\hline $\begin{array}{l}\text { Lymphoma/lymphoproliferative } \\
\text { disorders }\end{array}$ & 0 & 0 & $0.1(0.0$ to 0.8$)$ & 0 & 0 & $0.6(0.1$ to 4.6$)$ \\
\hline MACE & $1.3(0.3$ to 5.4$)$ & $0.6(0.2$ to 1.4$)$ & 0.8 (0.4 to 1.6$)$ & 0 & $1.2(0.3$ to 4.7$)$ & 0.6 (0.1 to 4.6$)$ \\
\hline All cause mortality (30-day rule)* & 0.7 (0.1 to 4.7$)$ & $0.6(0.2$ to 1.4$)$ & $0.4(0.2$ to 1.2$)$ & 0 & $1.2(0.3$ to 4.7$)$ & 0 \\
\hline
\end{tabular}

*30-day rule: deaths occurring within 30 days of the last dose.

Safety was assessed during months $0-6$ for the placebo group and months $0-24$ for the tofacitinib groups. Patients who advanced from placebo to tofacitinib are counted in the placebo group until advancement in the various studies-some patients advanced at month 3, while others advanced at month 6 unless they did not achieve a $20 \%$ improvement in swollen/ tender joint counts at month 3 , in which case they advanced to active treatment (ORAL Sync, ORAL Scan and ORAL Standard).

bDMARD, biological disease-modifying antirheumatic drug; IR, inadequate responders; MACE, major adverse cardiac events; N, number of patients included in analysis; NMSC, non-melanoma skin cancer; P3, phase III; SAE, serious adverse event.

Improvements in efficacy parameters were similar in bDMARD-IR tofacitinib-treated patients compared with TNFi-IR tofacitinib-treated patients from the ORAL Step study; this was expected given that these analyses included ORAL Step tofacitinib-treated patients $(n=399) .{ }^{27}$ In bDMARD-IR subpopulations treated with tofacitinib, ACR and DAS response rates at months 3 and 6 were generally similar to those reported for non-TNFi bDMARDs, including abatacept, rituximab and tocilizumab in TNFi-IR patients, except DAS endpoints for tocilizumab $8 \mathrm{mg} / \mathrm{kg} .{ }^{10} 13{ }^{14}$ In bDMARD-naive patients treated with tofacitinib, clinical efficacy endpoints were generally similar to those reported for bDMARDs in patients who were bDMARD-naive or with early RA. ${ }^{9}$ 34-41

More patients achieved efficacy endpoints at month 3 when treated with tofacitinib compared with placebo even after patients were stratified by exposure to previous TNFi. While tofacitinib was significantly greater versus placebo in patients exposed to bDMARDs for many endpoints, patients with $\geq 2$ previous TNFi exposure generally had poorer efficacy responses than bDMARD-naive patients and those with one previous TNFi exposure. The number of patients in the multiple TNFi group was less than the other TNFi exposure groups; for several endpoints, responses were numerically higher but not statistically significant for tofacitinib versus placebo in the multiple TNFi group-possibly attributable to the smaller sample sizes for each treatment group, therefore, conclusions must be made with caution. Baseline differences between the groups may impact on the differences in efficacy observed. Nevertheless, data in tofacitinib-treated bDMARD-IR patients were consistent with studies of bDMARDs that have generally shown less clinical response when a bDMARD is used after an IR to at least one previous bDMARD. ${ }^{10-21}$ Stratification by prior TNFi exposure also showed that ACR response rates in tofacitinibtreated bDMARD-IR patients were generally similar to
non-TNFi bDMARDs, ${ }^{10} \quad 13 \quad 14 \quad 1920$ but greater than TNFi. ${ }^{11} 12{ }^{18-21}$ The results of these analyses suggest that tofacitinib demonstrates efficacy compared with placebo in patients, irrespective of prior TNFi exposure; results were generally similar to those observed for bDMARDs.

In the P3 cohort, the tofacitinib safety profile appeared similar between treatment groups and between bDMARD-naive and bDMARD-IR subpopulations of patients with RA, with incidence rates that had overlapping 95\% CIs. Incidence rates for safety events were generally numerically higher for both tofacitinib doses versus placebo and tofacitinib $10 \mathrm{mg}$ twice daily versus tofacitinib $5 \mathrm{mg}$ twice daily for SIEs, HZ and malignancies (excluding NMSC), and in the bDMARD-IR versus bDMARD-naive subpopulations for discontinuations due to AEs, SAEs, HZ and malignancies (excluding NMSC). Patients that received glucocorticoids had a higher incidence of SAEs, discontinuation due to AEs, SIEs and $\mathrm{HZ}$ (all serious $\mathrm{HZ}$ occurred in patients receiving glucocorticoids); consistent with reports from RA patient databases of bDMARDs. ${ }^{42}{ }^{43}$ Opportunistic infections (excluding TB), TB, malignancies, lymphoma/lymphoproliferative disorders and deaths were uncommon in both bDMARD-naive and bDMARD-IR tofacitinib-treated patients in the P3 cohort; higher rates were observed for tofacitinib $10 \mathrm{mg}$ twice daily versus tofacitinib $5 \mathrm{mg}$ twice daily, except deaths (overlapping 95\% CIs). There is no apparent or consistent association between tofacitinib dose and risk of malignancy. ${ }^{44}$ In phase III studies, nearly all TB cases occurred in regions of high TB endemicity. ${ }^{45}$ Similar to the bDMARD-IR subpopulation, these safety events were also uncommon in the tofacitinib ORAL Step study ${ }^{27}$ and studies of bDMARDs in TNFi-IR populations. ${ }^{10} 11 \quad 13 \quad 14$ Compared with tofacitinib-treated patients in the bDMARD-naive subpopulation, these safety events of special interest were generally similar to those reported for bDMARDs in patients who were 
bDMARD-naive or with early RA. ${ }^{9}$ 34-41 46 The safety and efficacy profiles in bDMARD-naive and bDMARD-IR patients in the randomised controlled trials were generally similar to the data from tofacitinib LTE studies to date (data not shown ${ }^{47}$ ).

These pooled analyses provide a large data set for tofacitinib treatment groups in bDMARD-naive and bDMARD-IR subpopulations. The limitations of the pooling of data from studies with different designs and methodology may result in a heterogeneous patient population (despite similar inclusion/exclusion criteria), making it difficult to detect changes due to larger variations in the analysed populations. As patients were treated with placebo only for a short term, the placebo group had fewer patients and less exposure than the tofacitinib group in phase III studies, resulting in sample size differences for the comparisons at month 3. The studies included in these analyses were not designed for comparisons between bDMARD-naive and bDMARD-IR patients and patients with/without concomitant glucocorticoids; patients were not randomised according to this stratification, no formal statistical analyses were performed to compare efficacy or safety between these subpopulations, and conclusions were based on descriptive analyses only.

In summary, tofacitinib was effective in reducing the signs and symptoms of RA when used before or after bDMARDs. With a few exceptions, tofacitinib treatment resulted in greater efficacy responses in bDMARD-naive versus bDMARD-IR patients. The tofacitinib safety profile appeared similar between subpopulations. Taken together, these results suggest that tofacitinib provides an effective treatment option for both bDMARD-naive and bDMARD-IR patients.

Contributors KK, TH and EB were involved in conception and design of the study/ analyses. KK performed data and statistical analyses. CC-S, GB, PN, CAFZ, and RF were involved in data acquisition during the phase II, phase III and long-term extension clinical studies. CC-S, GB, PN, CAFZ, KS, KK, TH, EB and RF were involved in data interpretation and manuscript drafting, reviewing and development.

Funding This study was sponsored by Pfizer. Anne Marie Reid, PhD, of Complete Medical Communications provided editorial support under the guidance of the authors and was funded by Pfizer. Lisy Wang, Ryan DeMasi and Andrew Anisfeld, all employees and shareholders of Pfizer, provided intellectual input during the manuscript development.

Competing interests CC-S, PN, CAFZ and RF have received research grants and consultancy fees from Pfizer. GB is a member of the Speaker's Bureau for and has received research grants and consultancy fees from Pfizer. KS, KK, TH and EB are employees and shareholders of Pfizer.

Patient consent Obtained.

Ethics approval All studies were approved by the Institutional Review Boards (IRBs) and/or Independent Ethics Committees of each investigational centre or a central IRB. The studies were conducted in compliance with the Declaration of Helsinki and the International Conference on Harmonisation Good Clinical Practice Guidelines.

Provenance and peer review Not commissioned; externally peer reviewed.

Open Access This is an Open Access article distributed in accordance with the Creative Commons Attribution Non Commercial (CC BY-NC 4.0) license, which permits others to distribute, remix, adapt, build upon this work non-commercially, and license their derivative works on different terms, provided the original work is properly cited and the use is non-commercial. See: http://creativecommons.org/ licenses/by-nc/4.0/

\section{REFERENCES}

1 Anderson JJ, Wells G, Verhoeven AC, et al. Factors predicting response to treatment in rheumatoid arthritis: the importance of disease duration. Arthritis Rheum 2000;43:22-9.

2 Bresnihan B. Rheumatoid arthritis: principles of early treatment. J Rheumato/ Supp/ 2002;66:9-12. http://www.ncbi.nlm.nih.gov/pubmed/12435163

3 Emery P. Evidence supporting the benefit of early intervention in rheumatoid arthritis. J Rheumato/ Supp/ 2002;66:3-8. http://www.ncbi.nlm.nih.gov/pubmed/ 12435162
4 Furst DE, Pangan AL, Harrold LR, et al. Greater likelihood of remission in rheumatoid arthritis patients treated earlier in the disease course: results from the Consortium of Rheumatology Researchers of North America registry. Arthritis Care Res (Hoboken) 2011;63:856-64.

5 Heidari B. Rheumatoid Arthritis: early diagnosis and treatment outcomes. Caspian J Intern Med 2011;2:161-70. http://www.ncbi.nlm.nih.gov/pubmed/24024009

6 Jamal S, Patra K, Keystone EC. Adalimumab response in patients with early versus established rheumatoid arthritis: DE019 randomized controlled trial subanalysis. Clin Rheumatol 2009;28:413-19.

7 Quinn MA, Conaghan PG, Emery P. The therapeutic approach of early intervention for rheumatoid arthritis: what is the evidence? Rheumatology (Oxford) 2001;40:1211-20.

8 Quinn MA, Emery P. Window of opportunity in early rheumatoid arthritis: possibility of altering the disease process with early intervention. Clin Exp Rheumatol 2003;21:S154-7. http://www.ncbi.nlm.nih.gov/pubmed/14969068

9 Yilmaz S, Simsek I. Early intervention in the treatment of rheumatoid arthritis: focus on tocilizumab. Ther Clin Risk Manag 2013;9:403-8.

10 Emery $\mathrm{P}$, Keystone $\mathrm{E}$, Tony HP, et al. IL-6 receptor inhibition with tocilizumab improves treatment outcomes in patients with rheumatoid arthritis refractory to anti-tumour necrosis factor biologicals: results from a 24-week multicentre randomised placebo-controlled trial. Ann Rheum Dis 2008;67:1516-23.

11 Smolen JS, Kay J, Doyle MK, et al. Golimumab in patients with active rheumatoid arthritis after treatment with tumour necrosis factor alpha inhibitors (GO-AFTER study): a multicentre, randomised, double-blind, placebo-controlled, phase III trial. Lancet 2009;374:210-21.

12 Weinblatt ME, Fleischmann R, Huizinga R, et al. Efficacy and safety of certolizumab pegol in a broad population of patients with active rheumatoid arthritis: results from the REALISTIC phase IIIb study. Rheumatology (Oxford) 2014;51:2204-14.

13 Cohen SB, Emery P, Greenwald MW, et al. Rituximab for rheumatoid arthritis refractory to anti-tumor necrosis factor therapy: results of a multicenter, randomized, double-blind, placebo-controlled, phase III trial evaluating primary efficacy and safety at twenty-four weeks. Arthritis Rheum 2006;54:2793-806.

14 Genovese MC, Becker JC, Schiff M, et al. Abatacept for rheumatoid arthritis refractory to tumor necrosis factor alpha inhibition. N Engl J Med 2005;353:1114-23.

15 Du Pan SM, Scherer A, Gabay C, et al. Differential drug retention between anti-TNF agents and alternative biological agents after inadequate response to an anti-TNF agent in rheumatoid arthritis patients. Ann Rheum Dis 2012;71:997-9.

16 Genovese MC, Schiff M, Luggen M, et al. Efficacy and safety of the selective co-stimulation modulator abatacept following 2 years of treatment in patients with rheumatoid arthritis and an inadequate response to anti-tumour necrosis factor therapy. Ann Rheum Dis 2008;67:547-54.

17 Gomez-Reino JJ, Carmona L. Switching TNF antagonists in patients with chronic arthritis: an observational study of 488 patients over a four-year period. Arthritis Res Ther 2006;8:R29.

18 Greenberg JD, Reed G, Decktor D, et al. A comparative effectiveness study of adalimumab, etanercept and infliximab in biologically naive and switched rheumatoid arthritis patients: results from the US CORRONA registry. Ann Rheum Dis 2012:71:1134-42.

19 Malottki K, Barton P, Tsourapas A, et al. Adalimumab, etanercept, infliximab, rituximab and abatacept for the treatment of rheumatoid arthritis after the failure of a tumour necrosis factor inhibitor: a systematic review and economic evaluation. Health Technol Assess 2011;15:1-278.

20 Rendas-Baum R, Wallenstein GV, Koncz T, et al. Evaluating the efficacy of sequential biologic therapies for rheumatoid arthritis patients with an inadequate response to tumor necrosis factor-alpha inhibitors. Arthritis Res Ther 2011;13:R25.

21 Smolen JS, Kay J, Matteson EL, et al. Insights into the efficacy of golimumab plus methotrexate in patients with active rheumatoid arthritis who discontinued prior anti-tumour necrosis factor therapy: post-hoc analyses from the GO-AFTER study. Ann Rheum Dis 2014;73:1811-18.

22 Fleischmann R, Cutolo M, Genovese MC, et al. Phase Ilb dose-ranging study of the oral JAK inhibitor tofacitinib (CP-690,550) or adalimumab monotherapy versus placebo in patients with active rheumatoid arthritis with an inadequate response to disease-modifying antirheumatic drugs. Arthritis Rheum 2012;64:617-29.

23 Kremer JM, Bloom BJ, Breedveld FC, et al. The safety and efficacy of a JAK inhibitor in patients with active rheumatoid arthritis: results of a double-blind, placebo-controlled phase Ila trial of three dosage levels of CP-690,550 versus placebo. Arthritis Rheum 2009;60:1895-905.

24 Kremer JM, Cohen S, Wilkinson BE, et al. A phase Ilb dose-ranging study of the oral JAK inhibitor tofacitinib (CP-690,550) versus placebo in combination with background methotrexate in patients with active rheumatoid arthritis and an inadequate response to methotrexate alone. Arthritis Rheum 2012;64:970-81.

25 Tanaka Y, Suzuki M, Nakamura H, et al. Phase II study of tofacitinib $($ CP-690,550) combined with methotrexate in patients with rheumatoid arthritis and an inadequate response to methotrexate. Arthritis Care Res (Hoboken) 2011;63: 1150-8.

26 Tanaka Y, Takeuchi T, Yamanaka H, et al. Efficacy and safety of tofacitinib as monotherapy in Japanese patients with active rheumatoid arthritis: a 12-week, randomized, phase II study. Mod Rheumatol 2015;25:514-21. 
27 Burmester GR, Blanco R, Charles-Schoeman C, et al. Tofacitinib (CP-690,550) in combination with methotrexate in patients with active rheumatoid arthritis with an inadequate response to tumour necrosis factor inhibitors: a randomised phase 3 trial. Lancet 2013:381:451-60.

28 Fleischmann R, Kremer J, Cush J, et al. Placebo-controlled trial of tofacitinib monotherapy in rheumatoid arthritis. N Engl J Med 2012;367:495-507.

29 Kremer J, Li ZG, Hall S, et al. Tofacitinib in combination with nonbiologic DMARDs in patients with active rheumatoid arthritis: a randomized trial. Ann Intern Med 2013;159:253-61.

30 van der Heiide D, Tanaka Y, Fleischmann R, et al. Tofacitinib $(C P-690,550)$ in patients with rheumatoid arthritis receiving methotrexate: twelve-month data from a twenty-four-month phase III randomized radiographic study. Arthritis Rheum 2013;65:559-70.

31 van Vollenhoven RF, Fleischmann $\mathrm{R}$, Cohen $\mathrm{S}$, et al. Tofacitinib or adalimumab versus placebo in rheumatoid arthritis. N Engl I Med 2012;367:508-19.

32 Lee EB, Fleischmann R, Hall S, et al. Tofacitinib versus methotrexate in rheumatoid arthritis. N Engl J Med 2014;370:2377-86.

33 Wollenhaupt J, Silverfield J, Lee EB, et al. Safety and efficacy of tofacitinib, an oral janus kinase inhibitor, for the treatment of rheumatoid arthritis in open-label, longterm extension studies. J Rheumatol 2014;41:837-52.

34 Jones G, Sebba A, Gu J, et al. Comparison of tocilizumab monotherapy versus methotrexate monotherapy in patients with moderate to severe rheumatoid arthritis: the AMBITION study. Ann Rheum Dis 2010;69:88-96.

35 Emery P, Deodhar A, Rigby WF, et al. Efficacy and safety of different doses and retreatment of rituximab: a randomised, placebo-controlled trial in patients who are biological naive with active rheumatoid arthritis and an inadequate response to methotrexate (Study Evaluating Rituximab's Efficacy in MTX iNadequate rEsponders (SERENE)). Ann Rheum Dis 2010;69:1629-35.

36 Westhovens $\mathrm{R}$, Robles $\mathrm{M}$, Ximenes $\mathrm{AC}$, et al. Clinical efficacy and safety of abatacept in methotrexate-naive patients with early rheumatoid arthritis and poor prognostic factors. Ann Rheum Dis 2009;68:1870-7.

37 Bathon JM, Martin RW, Fleischmann RM, et al. A comparison of etanercept and methotrexate in patients with early rheumatoid arthritis. $N$ Engl I Med 2000;343:1586-93.

38 Emery P, Fleischmann RM, Moreland L, et al. Golimumab, a human anti-tumor necrosis factor and monoclonal antibody, injected subcutaneously every four weeks in methotrexate-naive patients with active rheumatoid arthritis: twenty-four-week results of a phase III, multicenter, randomized, double-blind, placebo-controlled study of golimumab before methotrexate as first-line therapy for early-onset rheumatoid arthritis. Arthritis Rheum 2009:60:2272-83.

39 Smolen J, Landewe RB, Mease P, et al. Efficacy and safety of certolizumab pegol plus methotrexate in active rheumatoid arthritis: the RAPID 2 study. A randomised controlled trial. Ann Rheum Dis 2009;68:797-804.

40 Breedveld FC, Weisman MH, Kavanaugh AF, et al. The PREMIER study: a multicenter, randomized, double-blind clinical trial of combination therapy with adalimumab plus methotrexate versus methotrexate alone or adalimumab alone in patients with early, aggressive rheumatoid arthritis who had not had previous methotrexate treatment. Arthritis Rheum 2006;54:26-37.

41 Klareskog L, van der Heijde D, de Jager JP, et al. Therapeutic effect of the combination of etanercept and methotrexate compared with each treatment alone in patients with rheumatoid arthritis: double-blind randomised controlled trial. Lancet 2004;363:675-81.

42 Listing J, Gerhold K, Zink A. The risk of infections associated with rheumatoid arthritis, with its comorbidity and treatment. Rheumatology (Oxford) 2013:52:53-61.

43 Strangfeld A, Eveslage M, Schneider $M$, et al. Treatment benefit or survival of the fittest: what drives the time-dependent decrease in serious infection rates under TNF inhibition and what does this imply for the individual patient? Ann Rheum Dis 2011;70:1914-20.

44 Curtis JR, Lee EB, Kaplan IV, et al. Tofacitinib, an oral Janus kinase inhibitor: analysis of malignancies across the rheumatoid arthritis clinical development programme. Ann Rheum Dis 2016;75:831-41.

45 Winthrop KL, Park SH, Gul A, et al. Tuberculosis and other opportunistic infections in tofacitinib-treated patients with rheumatoid arthritis. Ann Rheum Dis 2016;75:1133-8.

46 Strand V, Ahadieh S, French J, et al. Meta-analysis of serious infections with tofacitinib and biological treatment in rheumatoid arthritis clinical trials [abstract]. Arthritis Rheum 2014;66:S195.

47 Wollenhaupt J, Silverfield J, Lee EB, et al. Safety and efficacy of tofacitinib, an oral janus kinase inhibitor, for the treatment of rheumatoid arthritis in open-label, longterm extension studies. J Rheumatol 2014;41:837-52. 


\section{Erratum: Efficacy and safety of tofacitinib following inadequate response to conventional synthetic or biologic disease- modifying antirheumatic drugs}

Charles-Schoeman C, Burmester G, Nash P, et al. Efficacy and safety of tofacitinib following inadequate response to conventional synthetic or biologic disease-modifying antirheumatic drugs. Ann Rheum Dis 2016;75:1293-1301. The second trial number has been corrected to NCT00550446

Ann Rheum Dis 2017;76:611. doi:10.1136/annrheumdis-2014-207178corr1

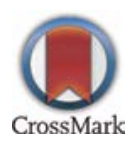

